\title{
A Comparative Study between Helicobacter Pylori Antigen in Stool with Histopathology and Rapid Urease Test of Endoscopic Biopsy in PUD Patient
}

\author{
Chowdhury MNI ${ }^{1}$, Kadir SMU ${ }^{2}$, Naher $\mathrm{Q}^{3}$, Chakraborty $\mathrm{L}^{4}$ \\ Hossain $\mathrm{MS}^{5}$, Rashid $\mathrm{MMA}^{6}$, Badiuzzaman $\mathrm{S}^{7}$
}

\begin{abstract}
Purpose: To assess stool antigen test as an early effective diagnostic tool like other methods for the diagnosis of $\mathrm{H}$. pylori infection in PUD patient.

Patients and Methods: This cross-sectional study was carried in a clinical pathology department of a tertiary level hospital. We included all patients with peptic ulcer disease those who were diagnosed by upper GIT endoscopy. Demographic variables and value of laboratory test including Stool antigen test, rapid urease test was studied in this study.

Result: A total of eighty-six patients were undergone for endoscopy after tested for Helicobactor pylori antigen in stool. Among 86 study subjects, Male was 56 (65\%) and female was $30(35 \%)$. The Mean $( \pm S D)$ age was found $38.53( \pm 10.40)$ years with range from 21 to above 60 years. Stool antigen test positive in 66 (66/86, 76.74\%), negative in $20(20 / 86$, 23.3\%). Rapid Urease Test positive in 76 (76/86, 88.4\%), negative in 20 (20/86, 11.6\%). Histopathology positive in $65(65 / 86,75.58 \%)$, negative in $21(21 / 86,24.42 \%)$. The result was statistically highly significant $(\mathrm{P}<0.001)$.
\end{abstract}

Conclusion: Stool antigen test (SAT) is an early effective diagnostic tool like other methods for the diagnosis of $\mathrm{H}$. pylori infection in our country.

CBMJ 2020 July: vol. 09 no. 02 P: 19-25

Key words: Peptic ulcer disease, stool antigen test, rapid urease test, endoscopy, pathology.

\section{Introduction}

Helicobacter pylori infection is usually without any symptoms, disease ranges from peptic ulcer disease (PUD), Gastic adenocarcinoma to gastric MALT lymphoma and simple gastritis. Helicobacter pylori $(\mathrm{H}$. pylori) infection is most common bacterial infections all over the world. ${ }^{1}$ Nearly $50 \%$ of the world's populations are affected. ${ }^{2}$ Helicobacter pylori are tropic for gastric epithelium and are found either attached to the surface epithelium or within the mucus coat. It elicits robust active inflammation and immune responses which continue throughout life or until the infection is cured. $^{3}$ The most important biochemical character of Helicobacter pylori is the abundant production of urease enzyme. This enzyme is one of the important factors for colonization. Most are asymptomatic, still $10-20 \%$ of $H$. pylori infected patients develop severe diseases during their lifetime including chronic gastritis, peptic ulcer disease, primary B-cell gastric lymphoma and gastric cancers. ${ }^{4}$ The prevalence of $\mathrm{H}$. pylori infection is high in Bangladesh. $60 \%$ are infected by the age of three months and $80 \%$ are infected by three years of age. ${ }^{5}$ The prevalence among the middle-aged adults is over $80 \%$ in many developing countries and $20-50 \%$ in the

1. Dr. Md. Nazrul Islam Chowdhury, Assistant Professor (Clinical Path.), National Institute of Ophthalmology, Dhaka.

2. Dr. Syeed Mehbub UI Kadir, Assistant Professor (Ophth.), Sheikh Fazilatunnessa Mujib Eye Hospital and Training Institute, Gopalgonj.

3. Dr. Qamrun Naher, Consultant Sonologist, Medinova Medical Service and Lab Aid Diagnostic Ltd. Dhaka.

4. Dr. Lokesh Chakraborty, Assistant Professor (Clinical Path.), National Institute of ENT, Dhaka.

5. Dr. Mohammad Shahadat Hossain, Emergency Medical Officer, 300 Beded General Hospital, Narayanganj.

6. Dr. Md. Mamun-Ar-Rashid, Junior consultant (Pathology), 300 beded General Hospital, Narayanganj.

7. Dr. Shaikh Badiuzzaman, Assistant Professor (Clinical Path.), National Institute of Laboratory Medicine, Dhaka.

Address of correspondence:

Email: nazrulnic21.mnic@gmail.com 
developed countries. $^{6}$ Gastric urease enzyme allows the organism to colonize the acidic stomach. Urease enzyme is an important indirect biomarker for the presence of $\mathrm{H}$. pylori. It is the basis of rapid urease test (RUT) and urea breath test (UBT), and it is also used as an antigen for serological detection. ${ }^{4,7}$ Histology, culture and rapid urease test are the invasive tests requiring endoscopy and biopsy. On the other hand serology, urea breath test and stool antigen tests are the noninvasive tests. ${ }^{8,9}$ Urea breath test is not available in our country. So, it has become necessary to validate another reliable non-invasive test that is stool antigen test. $\mathrm{H}$. pylori infection is an important medical problem in the whole world including Bangladesh. Diagnosis of the disease remains dormant. $\mathrm{H}$. pylori are also related to gastric carcinoma. Early detection of $\mathrm{H}$. pylori is very much important for diagnosis of the disease and successful treatment. The most reliable the non-invasive test is urea breath test. Still the test is not currently available in our country. So, it becomes necessary to validate another reliable modality of noninvasive test. There is no previous study in our country to assess the accuracy of monoclonal Stool Antigen Test (SAT). SAT is an easy noninvasive test requiring shorter time and low cost. $\mathrm{H}$. pylori specific stool antigen can be tested through available immunochromatographic (ICT) strip. The test is specific and reliable, may be an alternative to urea breath test. This study was aimed to assess stool antigen test as an early effective diagnostic tool like other methods for the diagnosis of $\mathrm{H}$. pylori infection in PUD patient.

\section{Methods:}

This cross-sectional study was conducted in the department of clinical pathology of Bangabandhu Sheikh Mujib Medical University (BSMMU) from July 2013 to June 2014. Study population included all clinically suspected $H$. pylori infected patients attending for upper GIT endoscopy. Sample size was determined by power analysis for a single proportion. We hypothesized that sensitivity of stool antigen test to predict $\mathrm{H}$. pylori infection will be $90 \%$ or greater. The sample size was calculated for a power level of greater than $80 \%$, an error of 0.05 , and an expected sensitivity of more than $70 \%$ based on previous published article. ${ }^{2}$ The demographic (age, and gender) and clinical data with SAT, RUT, endoscopic biopsy for Upper GIT, H \& E stain, and histopathological analysis (Figure 1 \& 2) were recorded in a pre-designed data-sheet and analyzed for the study. Patients having upper abdominal pain, abdominal discomfort, anorexia, nausea, vomiting and belching and were enrolled for upper Gl endoscopy. Among them who were found ulcer in the stomach or in duodenum were enrolled in our study to detect $\mathrm{H}$. pylori by stool antigen test, rapid urease test, endoscopy, and histopathology. Endoscopy of upper GIT was performed from suspected $\mathrm{H}$. pylori infected patient. The endoscopic biopsy was inoculated into urea agar base bottle carefully by the help of sterile needle and change of the color of the broth was observed and recorded. SAT done with stool sample and result was observed and recorded. The whole procedure was explained to the patient and informed written consent was taken. All samples received for analysis was considered potentially positive for infectious agents including HIV and the hepatitis B virus. Universal precaution was maintained. The stool antigen test was done from stool sample and data was recorded in tabulated form of data sheet. The rapid urease test was done with endoscopic biopsy and result was recorded in data sheet. Histopathological report for $\mathrm{H}$. pylori was collected and recorded in data sheet. The stool antigen test result was compared with result of rapid urease test and histopathological report. Both histopathology and rapid urease test positive were considered as disease positive and both or either one of them negative results were considered as true negative. Thus, true positive, true negative and false positive, false negative results were recorded and sensitivity, specificity, positive and negative predictive values of stool antigen test was 
calculated by unpaired t-test, chi square test and validity test. Data were edited, cleaned and analyzed by statistical package for social science (SPSS-17.0). The test was considered significant when $P$ value $<0.005)$.
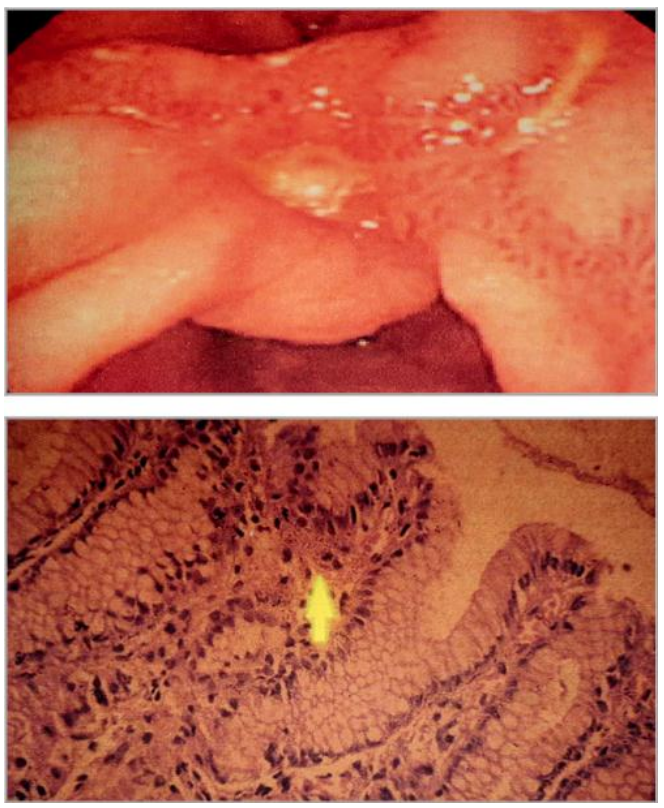

Figure 1 \& 2: Photographs of Endoscopic snap shot showing ulcer in stomach, $\mathrm{H}$ \& E stain of tissue from endoscopic biopsy showing $\mathrm{H}$. pylori in the crypt.

\section{Results:}

We tested antigen in stool for the detection of $\mathrm{H}$. pylori in 86 peptic ulcer disease patients. Through endoscopy in the Department of Gastroenterology those patients found ulcer in the stomach or duodenum were enrolled in the study. Endoscopic biopsy was taken for histopathology and rapid urease test. In the study, we compared SAT result with RUT and histopathology of endoscopic biopsy. $\mathrm{H}$. pylori was defined when both RUT and Histopathology were positive and both or either one of them negative were considered as negative for the study. The Mean $( \pm S D)$ age was found $38.53( \pm 10.40)$ years with range from 21 to above 60 years. The age distribution of the study patients and it was observed that majority (28/86, $32.6 \%$ ) were age belonged to $31-40$ years (Graph-1).

Graph-1: Distribution of age groups of study subjects.

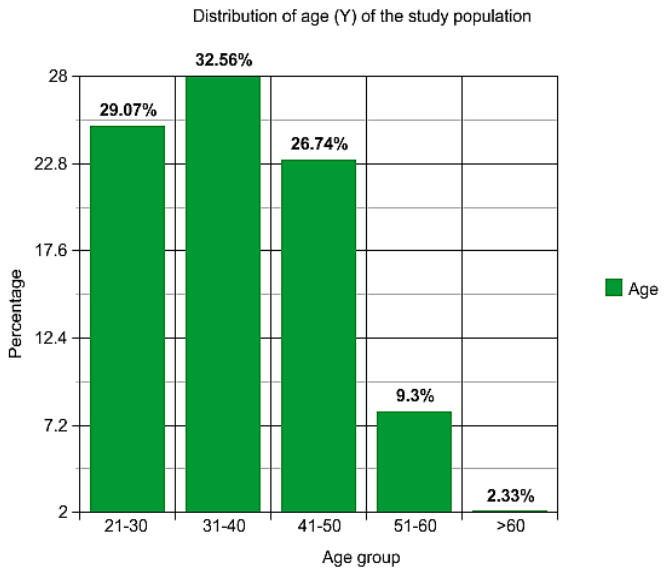

The gender distribution included male (65.1\%) and female (34.9\%). Table-1 shows laboratory findings of the study population in different tests among 86 patients. Stool antigen test positive in $66(76.74 \%)$ cases, negative in 20 (23.3\%) cases. Rapid Urease Test positive in $76(88.37 \%)$ cases, negative in $10 \quad(11.63 \%)$ cases. Histopathology positive in 75 (87.21\%) cases, negative in 11 (12.79\%) cases. Out of 86 patients, 66 were SAT positive, and 20 were SAT negative. Both RUT and histopathology positive were in 73 (84.9\%) and negative were in $13(15.1 \%)$ cases. In 66 positive cases of SAT, 63 were true positive and 03 were negative (false positive). In 20 cases of SAT negative test, true negative was 10 and false negative was 10 . These findings were statistically highly significant $(p<0.0001)$. Histopathology was positive in 75 (87.2\%) and negative in 11 (12.8\%) cases. 
Table-1: Laboratory findings of the study population in different tests.

\begin{tabular}{|l|c|c|}
\hline Variable & Elderly $(\mathrm{n}=31)$ & Non-elderly $(\mathrm{n}=40)$ \\
\hline Stool antigen test & & \\
\hline - Positive & 66 & 76.74 \\
\hline - Negative & 20 & 23.26 \\
\hline Rapid Urease Test & & \\
\hline - Positive & 76 & 88.37 \\
\hline - Negative & 10 & 11.63 \\
\hline Histopathology & & \\
\hline - Positive & 75 & 87.21 \\
\hline - Negative & 11 & 12.79 \\
\hline
\end{tabular}

In 66 SAT positive cases, RUT positive in 65 cases and negative was in 01 case (false positive). Histopathology was positive in 63 cases and negative was in 03 cases. In 20 SAT negative cases, RUT was positive in 11 cases and negative in 09 cases. histopathology was positive in 12 cases (false negative of SAT test), and histopathology was negative was in 08 cases (true negative). These findings were statistically highly significant $(P<0.001)$ (Table-2). The result shows in Table-3 that out of 86 patients 63 were SAT positive and 10 were negative. Both RUT and Histopathology positive were in 73 and negative were in 13. True positive was in 63 , false positive was in 03 . True negative was in 10 and false negative were in 10 . These findings were statistically highly significant $(\mathrm{P}<0.001)$.

Table-2: Association between SAT with RUT and Histopathology findings.

\begin{tabular}{|l|l|l|l|l|}
\hline $\begin{array}{l}\text { Test of } \\
\text { Reference }\end{array}$ & \multicolumn{2}{|c|}{$\begin{array}{c}\text { Stool Antigen Test } \\
\text { (SAT) }\end{array}$} & Total & $p$-value \\
\hline & Positive (n-66) & Negative (n-20) & & \\
\hline RUT: & & & & \\
\hline Positive & $65(\mathrm{TP})$ & $11(\mathrm{FN})$ & 76 & $<0.001$ \\
\hline Negative & $01(\mathrm{FP})$ & $09(\mathrm{TN})$ & 10 & \\
\hline Histopathology: & & & & \\
\hline Positive & $63(\mathrm{TP})$ & $12(\mathrm{FN})$ & 75 & $<0.001$ \\
\hline Negative & $03(\mathrm{FP})$ & $08(\mathrm{TN})$ & 11 & \\
\hline
\end{tabular}

(TP-True Positive, FP-False positive, TNTrue negative, FN-False negative) ( $\mathrm{s}=$ significant. Chi square test was done to measure the level of significance. P-value was statistically highly significant).

The result shows in Table-3 that sensitivity, specificity, positive predictive values and negative predictive values and accuracy of SAT with RUT and Histopathology are $86.3 \%, \quad 77.00 \%, 95.45 \%, 50.00 \%$ and $85.00 \%$ respectively.

Table-3: Sensitivity, specificity, positive predictive values, negative predictive values and accuracy of SAT with RUT and Histopathology $(n=86)$.

\begin{tabular}{|l|c|c|c|c|c|}
\hline Test & $\begin{array}{c}\text { Sensitivity } \\
(95 \% \mathrm{Cl})\end{array}$ & $\begin{array}{c}\text { Specificity } \\
(95 \% \mathrm{Cl})\end{array}$ & $\begin{array}{c}\text { PPV } \\
(95 \% \mathrm{Cl})\end{array}$ & $\begin{array}{c}\text { NPV } \\
(95 \% \mathrm{Cl})\end{array}$ & $\begin{array}{c}\text { Accuracy } \\
(95 \% \mathrm{Cl})\end{array}$ \\
\hline $\begin{array}{l}\text { Stool antigen } \\
\text { test (SAT) } \\
\text { with RUT and } \\
\text { Histopathology }\end{array}$ & $86.3 \%$ & $77.00 \%$ & $95.45 \%$ & $50.00 \%$ & $85.00 \%$ \\
\hline
\end{tabular}

Out of 86 patients' sensitivity, specificity, positive predictive values and negative predictive values and accuracy of SAT with Histopathology are 84.0\%, 72.73\%, 95.45\%, $40.0 \%, 82.56 \%$ respectively. On the other hand, sensitivity, specificity, positive predictive values and negative predictive values and accuracy of SAT with RUT are $85.53 \%$, 90.0\%, 98.48\%, 45.0\%, 86.05\% respectively and with RUT and histopathology are $86.3 \%, 77 \%, 95.45 \%$, $50 \%$ and $85 \%$ respectively (Graph-2). 
Graph-2: Comparison of individual sensitivity, specificity, positive predictive values, negative predictive values and accuracy of SAT with Histopathology and Histopathology with RUT ( $n=86)$.

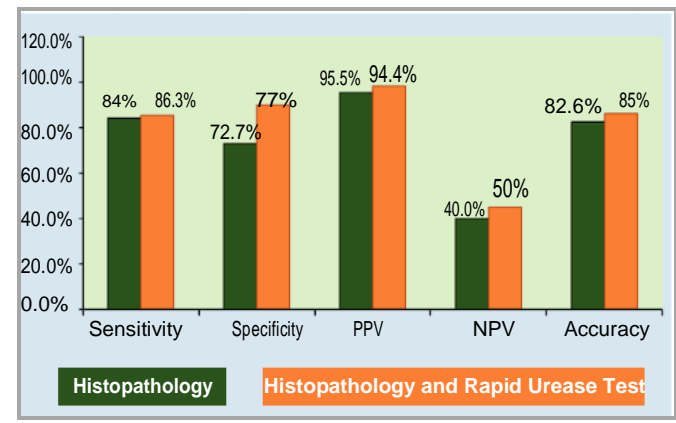

\section{Discussion:}

$H$. pylori infection is an important medical problem in the whole world including Bangladesh. Nearly $50 \%$ of the world's populations are affected. The bacteria cause peptic ulcer disease in young life and have a long latent period. So that patients are asymptomatic before appearing clinical features. Helicobacter pylori is thought to reside normally only in the stomach. ${ }^{10} \mathrm{H}$. pylori infection is usually without any symptoms, disease ranges from peptic ulcer disease (PUD), gastric adenocarcinoma to gastric MALT lymphoma and simple gastritis. ${ }^{11}$ We tested antigen in stool for the detection of $\mathrm{H}$. pylori with $\mathrm{ABON}$ lateral flow immunochromatographic test device in 86 peptic ulcer disease patients. Through endoscopy in the Department of Gastroenterology those patients who were found ulcer in the stomach or duodenum were enrolled in the study. In the study we compared SAT result with RUT and histopathology of endoscopic biopsy. $\mathrm{H}$. pylori status was defined when both RUT and histopathology were positive and both or either one of the tests negatives was considered as negative. There are many publications comparing SAT with different invasive and noninvasive tests for detection of $\mathrm{H}$. pylori. But there is no known similar study done in comparing SAT with RUT and Histopathology in PUD patients in
Bangladesh. In our study, the mean age was found $38.53 \pm 10.40$ years with range from 21 to above 60 years and the highest incidence of PUD patients were belonged to 31-40 years. A study by Islam MDU et al., found that age between 16-70 years. Of the highest incidence were aged 21-30 and mean age was 37.98 years. $^{12}$ These finding are near similar to our study. The gender distribution of the study patients showed $65.1 \%(56 / 86)$ male and 34.9\% (30/86) female out of 86 patients. A study where they found distribution of gender among 63 patients was male-31(49.2\%) and female was $32(50.8 \%)$ which coincides our study. ${ }^{13}$ In our study we compared stool antigen test with RUT and histopathology of endoscopic biopsy. Among 86 patients we found stool antigen test was positive $66(76.7 \%)$ and negative $20(23.3 \%)$, rapid urease test was found positive 76 (88.4\%) and negative 10 (11.6\%) and histopathology was positive 65 (75.58\%) and negative 21 (24.42\%). Stool antigen tests (SAT) were positive for antral gastritis (63.4 \%), gastric ulcer (66.7\%), duodenal ulcer $80 \%$ and esophagitis $75 \%$. $66.7 \%$ patients were positive by SAT test. ${ }^{13}$ In our study we found the sensitivity, specificity, positive predictive and negative predictive values and the accuracy of SAT with both RUT and Histopathology were $86.3 \%, \quad 77.00 \%, 95.45 \%, 50.00 \%$ and $85.00 \%$ respectively. A study reported that the sensitivity, specificity, positive predictive and negative predictive values of SAT with both RUT and Histopathology were $69 \%$, $86 \%, 92 \%, 53 \%$ and $92 \%$ respectively. ${ }^{2}$ Another study found the sensitivity, specificity, positive predictive and negative predictive values and the accuracy of SAT with both RUT and Histopathology were found $94 \%$, $90 \%, 93 \%, 92 \%$ and $92 \%$ respectively. $^{14}$ The sensitivity, specificity, positive predictive and negative predictive values of SAT with Urea breath test were $88.0 \%, \quad 87.5 \%, \quad 88.0 \%$ and $87.5 \%$ respectively. ${ }^{15}$ Histopathology showed high overall performance in adults and children with sensitivity and specificity $100 \%$ and $90 \%$, respectively. Sensitivity, specificity, and accuracy for stool antigen test were $87.8 \%, 75 \%$ and $82 \%$, respectively. 
Correlation of RUT, serology (IgG), histopathology and stool antigen tests with PCR were 0.82, 0.32, 0.91 and 0.63, respectively. ${ }^{16}$ The mentioned results are consistent with our study. This study found the sensitivity, specificity, positive predictive and negative predictive values and the accuracy of SAT with RUT were $85.53 \%$, $90.0 \%, \quad 98.48 \%, \quad 45.0 \%$ and $86.05 \%$ respectively. Qadeer AS et al., found the sensitivity, specificity, positive predictive value and negative predictive value of stool antigen test with rapid urease test was $89.1 \%, \quad 92.6 \%, \quad 91.1 \%$ and $90.9 \%$ respectively. ${ }^{17}$ These results are consistent with our study. On the other hand, we found the sensitivity, specificity, positive predictive value and negative predictive value of stool antigen test with histopathology were $84.0 \%, 72.73 \%, 95.45 \%, 40.0 \%$ and 82.56 $\%$ respectively. The study also reported on the sensitivity, specificity, positive predictive value and negative predictive value of stool antigen test with histopathology that were $92.8 \%, \quad 89.6 \%, \quad 86.7 \%$ and $94.5 \%$ respectively. ${ }^{17}$ Our results are consistent with their studies.

Recently many reliable methods for detecting $\mathrm{H}$ pylori infection are available. However, since invasive methods require endoscopy, they are not suitable for primary care physicians. In the absence of endoscopy facilities, primary care physicians require non-invasive methods to diagnose $\mathrm{H}$ pylori infection. Stool antigen test is an easy and quick procedure that does not require expensive equipment's and can be used as an alternative to detect $\mathrm{H}$ pylori infection. This method also offers advantages as a simpler sampling method. The stool test seems to meet the requirements of general practitioners who treat most patients infected with $\mathrm{H}$ pylori, because it is easy to perform and requires no blood samples.

\section{Conclusion:}

Helicobacter pylori stool antigen test is noninvasive technique, inexpensive, and portable in routine laboratory and resulted accurate diagnosis for the detection of $\mathrm{H}$. pylori infection in PUD patients prior to endoscopy. Stool antigen test would be useful and reliable diagnostic tool in our routine laboratory practice where endoscope is not available. It is important to eradicate the $\mathrm{H}$. pylori infection to reduce the risk of gastric cancer development.

Limitations of the study: The study time was limited; the sample size was small, and the sample was collected from only one tertiary center that did not reflect the whole population.

\section{Ethical consideration:}

The study protocol was approved by the Institutional Review Board (IRB) of BSMMU, Dhaka.

\section{References:}

1. Calvet $X$, Lehours $P$, Lario $S$, Megraud $F$. Diagnosis of Helicobacter pylori Infection. Helicobacter, 2010; 15 (1):7-13.

2. Calvet X, Quesada M, Sanfeliu I, Salceda F, Rossello M, Monstserrat $A$ et al. Diagnosis of Helicobacter pylori infection in dyspeptic patients by stool antigen detection usefulness of a new monoclonal enzyme immunoassay test. Digest Liver Disease 2004:36:446-447.

3. Malfertheiner $P$, Megraud $F$, O'Morain $C$ Bazzoli F, El-Omar E, Graham D, Hunt R, Rokkas T, Vakil N, Kuipers EJ. Current concepts in the management of Helicobacter pylori infection: the Maastricht III Consensus Report. Gut. 2007 Jun;56(6):772-81.

4. Megraud F, Floch P, Labenz J, Lehours P. Diagnostic of Helicobacter pylori infection. Helicobacter 2016; 21 (1):8-13.

5. Mahalanahish D, Rahaman MM, Sarker SA, Bardhan PK. Helicobacter pylori infection in young in Bangladesh- Prevalence, socioeconomic and nutritional aspect. International Journal of Epidemiology, 1996; 25(4): 894-898.

6. Everhart JE, Kruszon-Moran D, Perez-Perez GI, Tralka TS, McQuillan G. Seroprevalence and ethnic differences in Helicobacter pylori infection among adults in the United States. $J$ Infect Dis 2000;181(4):1359-63. doi: $10.1086 / 315384$. 
7. Vogiatzi $P$, Cassane M, Luzzi I, Lucchetti $C$. Otovas Jr L, Giordano A. Helicobacter pylori as a class I carcinogen: Physiopathology and management strategies. $J$ of Cellular Biochemistry 2007;102(2): 264-73.

8. Cirak MY, Akyon Y, Megraud F,Diagnosis of Helicobacter pylori. Helicobacter 2007;12(1):4-9.

9. Chey WD, Wong CY. American College of Gastroenterology Guideline on the Management of Helicobacter pylori Infection', American Journal of Gastroenterology, 2007;102:1808-1825.

10. Parsonnet J, Shmuely $H$, Haggerty $T$. Fecal and oral shedding of Helicobacter pylori from healthy infected adults. $J$ of $A m$ Med Association 1999;282 (23):2240-2245.

11. Basso D, Plebani M, Kusters $G$. Pathogenesis of Helicobacter pylori infection, Helicobacter 2010;15(11):14-20.

12. Islam MDU, Rahman $S H Z$, Shamsuzzaman SM, Muazzam N, Kibria SG, Hossain MT, Ahmed N, SarkarAR, Nahar S. A Comparative Study Among Different Invasive Methods For The Diagnosis of Helicobacter Pylori' Faridpur Medical College Journal, 2010; vol. 5 no. 1, pp. 21 24.

13. Syam AF, Rani AA, Abdullah M, Manan $C$, Makmun $D, M$. Simadibrata $D$ et al. Accuracy of Helicobacter pylori stool antigen for the detection of Helicobacter pylori infection in dyspeptic patients. World $J$ Gastroenterol 2005;1(3):386-388.

14. Trevisani L, Sartori $S$, Rossi MR, Gilvani $F$, Rossi MR, Ruina $M$ et al. Evaluation of a new rapid immunoassay for the detection of Helicobacter pylori in faeces: A prospective pilot study. Aliment Pharmacol Ther. 2005;21:485-89.

15. Silva J, Villares $C A$, Monteiro $M$, Colaúto $C$, Santos AF, Mattar R. Validation of A Rapid Stool Antigen Test for Diagnosis Of Helicobacter pylori Infection. Rev. Inst. Med. Trop. Sao Paulo. 2010; 52(3):125-128.

16. Pourakbari B, Ghazi M, Mahmoudi $S$, Mamishi S, Azhdarkosh $H$, Najafi $M$ et. al. Diagnosis of Helicobacter pylori infection by invasive and noninvasive tests. Braz. J. Microbiol 2013;. 44 (3):795-98.
17. Qadeer AS, Kharal SA, Baig MF, Badvi JA, Durani MA. Detection of Helicobacter pylori antigen in stool. $J$ of Liaquat University of Med Sci 2009;08(02):126-30. 